\title{
Who has high science capital? An exploration of emerging patterns of science capital among students aged 17/18 in England
}

\begin{abstract}
Increasing and diversifying participation in science remains a key educational policy concern for governments across the world. Science capital has been proposed as a useful theoretical lens that can explain patterns in science aspirations among young people aged 11-16 - but to date it has not been explored in relation to educational outcomes among older age groups. This paper reports findings from a new survey of 7,013 17/18 year old English secondary school students. It replicates and extends previous findings, showing that among older students, levels of science capital remain patterned by gender, ethnicity, cultural capital and science set. Comparison of effect sizes with previous findings from a younger cohort also reveal that, overall, levels of science capital seem to decrease with age. However, the proportion of students with 'high' science capital remained stable while the proportion of those with low science capital increased. Analysis also revealed a small but significant increase in the proportion of boys with high science capital. Findings confirm that science capital relates to outcomes at age $17 / 18$, with high science capital students being relatively more likely to be pursuing postcompulsory STEM qualifications and routes. Implications for educational policy and practice are identified, particularly with regard to goals of diversifying and increasing science participation.
\end{abstract}

Keywords: science capital; survey; aspirations; intentions; cultural capital 


\section{Introduction}

The perceived lack of young people leaving education systems around the world adequately qualified to work in Science, Technology, Engineering and Mathematics (STEM) fields remains at the forefront of educational policy agendas and reforms (e.g. Rothwell 2014; Royal Academy of Engineering, 2016; UK Commission for Employment and Skills, 2014). While the UK performs poorly on a number of key indicators of success in STEM, including literacy, mathematics skills, and ICT at school as well as poor retention rates for $\mathrm{PhD}$ researchers (BIS, 2014), these are not isolated issues unique to the UK, with similar trends documented in the US, Canada, and other European countries. Specifically in the UK, there is widely accepted urgency to broaden the gender, ethnic and social class profile of those who study STEM post-16 (when it becomes no longer compulsory), particularly in the physical sciences and engineering, where women, some minority ethnic and working-class communities are starkly under-represented (Institute of Physics, 2015; National Audit Office, 2018; Smith, 2010a,b).

Important arguments have been made regarding the necessity of ensuring that high levels of STEM literacy exist across the population (Institute of Physics, 2015; National Audit Office, 2018; Osborne, 2007; Royal Academy of Engineering, 2016). In our research, we take the view that it is desirable to achieve a more equitable spread of STEM literacy in society because of the symbolic capital that STEM disciplines offer and because they can facilitate agency and the re/production of privilege (Bourdieu 2010).

Despite sustained attempts to increase and to broaden participation rates in postcompulsory science (e.g. Smart \& Rahman, 2009) and the variety of interventions trialled in recent years (e.g. Calabrese Barton \& Tan, 2010; Daly, Grant, \& Bultitude, 2009; Darke, Clewell, \& Sevo, 2002; Haussler \& Hoffmann, 2002; Luehmann, 2009), patterns of inequitable 
participation persist. Understanding the factors shaping STEM participation is, therefore, a key priority area for the UK government (HM Treasury 2011) and indeed, other Western developed nations (e.g. US President's Council of Advisors on Science and Technology 2010).

The current patterned nature of science participation: Understanding contributing factors

Existing research has identified a range of factors shaping science attitudes and aspirations among young people aged 10-16 in compulsory education. For instance, our previous studies found that the majority of young people age 10-18 find school science interesting, but that this does not translate into aspirations to work in science (e.g. Author 3 et al., 2016). As discussed further below, the likelihood of a young person aspiring to science and/or expressing a science identity is influenced by how much 'science capital' they have (Author 2 et al., 2015), but is also shaped by parenting approaches (Author 2 et al., 2012) and interactions of gender, class and ethnicity (Author 2 et al, 2015; Author 2 \& Author 1, 2015). Our research has also pointed to how particular practices within compulsory education in England also play a part in shaping young people's perception of whether science is 'for me', or not, such as the stratification of school science routes at age 15/16 (Author 2 et al., 2016), gatekeeping practices around post-compulsory science A level science (Author 2 et al., 2017) and the patchy and patterned nature of careers education (Author $1 \& 2,2017$ ). As other work has also found, the culture of science and the dominant perceptions of who/what is recognised as being 'good at science' also play a key role (Author 2 et al, 2017; Mendick, 2005; Wong, 2012) in addition to family support and values (e.g. Mujtaba \& Reiss, 2014, 2016; VedderWeiss, 2018).

Perceptions and practices that support a view of STEM subjects as being 'difficult' and only for the 'clever few' (Author 2 et al., 2017; Author 3, 2013) also play a part. These issues 
are compounded by gendered inequalities, with Carlone's (2003) research showing how physics teachers in the US attributed high performance results to male students' 'raw talent' while female students' high attainment was explained as due to their diligence and 'hard work' (see also Gonsalves, Danielsson, \& Pettersson, 2016 inter alia, on gender and physics).

Theoretical framework: Using a science capital lens

A body of research is emerging showing that the likelihood of a young person aspiring to a career in science is strongly related to how much science capital they have. The concept of science capital builds on the sociological theory of Bourdieu and has been variously described as a conceptual explanatory device to collate science-specific forms of 'cultural capital', 'social capital', and habitus (socialized, embodied dispositions) (Author 2 et al., 2015; Author 3 et al., 2016). The concept of science capital thus encompasses more than just science interests, attitudes or motivations - rather it comprises specific forms of science-related cultural capital and social capital, including dispositions, behaviours and social contacts, that have been previously found (ibid.) to relate strongly to the likelihood of a young person participating in post-compulsory science and espousing a science identity (that is, seeing themselves and being recognised by others as a 'science person').

Since introduced (Author 2 et al., 2014; 2015), the concept has been taken up and further extended. For example Gokpinar and Reiss (2016) propose that science capital is provided to students primarily at a 'pre-reflexive' level which can then translate into capabilities and functions through conversion factors (e.g. out of school family visits to science museums or helping with homework). Other work has confirmed the original theoretical framework through multi-level modelling results (Mujtaba, Sheldrake, Reiss, \& Simon, 2018). Science capital has also been found to relate to school science attitudes and engagement (e.g. 
Author 2 et al., 2015; Aschbacher, Li, \& Roth, 2010; Mujtaba et al., 2018; Vedder-Weiss, 2018). For example, a student aged 13/15 (Y9) with a family member working in a sciencerelated job is more than twice as likely to report a 'high' science aspiration as those who do not (Author 2 et al., 2015). Yet as our previous research has suggested, science capital is unevenly spread across school students aged 11-16 in England. Science capital has also been shown to be related to engagement in science activities in informal settings, such as museums (Essex \& Haxton, 2018).

Yet to date, the concept of science capital has overwhelmingly been explored and applied within the context of compulsory education and, to a lesser extent, within informal science learning settings. Less is known about whether science capital can explain or shed light on post-compulsory STEM participation and how it may change (or not) over time. For instance, is science capital 'fixed' or does it increase or decrease over time? Moreover, we suggest that developing a better understanding of young people's "science capital" (and how it may be leveraged, generated, and differentially embodied and valued across time and different learning contexts, fields, and social groups) may be a useful and valuable part of ongoing efforts to improve agency, social mobility, and social justice science education work with underserved communities. In other words, we are interested in the various ways that science might constitute a form of capital that can be activated and mobilised through different learning contexts to reinforce, perpetuate, or even challenge social inequalities and the ways in which shifts in the dominant values of a given field may open up, or close down, the recognition, valuing and leveraging of different forms of students' capital, to promote or restrict student engagement with science. 
This paper aims to contribute to knowledge in the field of STEM participation through an analysis of the extent to which levels of science capital are patterned among an older cohort (17/18 years old) by student background characteristics. Additionally, we analyze differences in future post-18 study intentions, extending results published to date regarding the relationship between science capital and post-16 intentions among students aged 11-16. Specifically, we ask:

- How/do levels of science capital among a new, older cohort of students (aged 17/18) differ, or not, from those found previously among younger students, age 11-16? How do these patterns relate to gender, ethnicity, cultural capital and previous experiences of school science?

- Do overall levels of science capital increase, decrease or stay the same at age $17 / 18$ ?

- Is there an association between high levels of science capital and students' science outcomes at age 17/8 and their future (post-18) study intentions?

\section{Methods}

The [project name] project is a 5-year longitudinal study funded by the UK's Economic and Social Research Council ${ }^{\text {ii }}$. It follows on from the previous [name] study, which investigated children's science and career aspirations from age 10-14, with the present study extending the tracking of this cohort from 14-19 years old. The overall project employs a mixed methods approach in order to generate both a breadth and depth of data. The [name] study involves a quantitative online survey of the cohort and repeat (longitudinal) interviews with a selected subsample of students and their parents. This paper reports on the final phase of the [name] study, which includes a survey and interviews with students age 17/18 years old (Year 13), 
collected Autumn 2016. The focus of the current paper is on a subset of quantitative survey data gathered during this final phase.

\section{Survey sample and overview}

A questionnaire exploring students' aspirations and science attitudes, the development and validation of which have been described and validated elsewhere (Author 3 et al., [2014; 2011]), was revised, validated and piloted with 200 students before being administered to a national sample of 7,900 17/18-year-old students. A sampling profile of 3,000 schools was created using the Department of Education Key Stage 5 performance data and a sample structure built along school gender (single sex vs. mixed), type (state vs private), geographical distribution and attainment at A level/vocational qualification. Schools were invited to arrange for one or more mixed attainment classes, science sets or tutor groups of pupils to complete the questionnaire. Schools were also encouraged to invite additional classes (e.g. a spread of top, middle and bottom science sets, or entire cohorts) to participate in order to receive a more comprehensive picture of their students' attitudes towards science and their career aspirations.

Students from 265 schools (approximately $9 \%$ of those sampled) completed the survey (237 state-maintained schools; 28 independent schools). This sample was roughly proportional to the overall national distribution of schools in England by region, school type, attainment and free school meals (as a measure of socioeconomic status). These schools represented all 9 Government Office Regions in England. The schools came from a range of Index of Multiple Deprivation $^{\mathrm{iii}}$ (IMD) deciles, though 58\% were in the top half (deciles 6-10). In addition, the sample was roughly proportional to the overall distribution of schools in England in terms of 
attainment (though with more in the middle band and fewer in the lowest two bands). $88 \%$ of the schools were mixed-sex and slightly over half (53\%) were sixth forms in academies. There were also $25 \%$ (non-academy) schools and 17\% Further Education colleges (6\% sixth form colleges).

Following data cleansing (which involved removal of duplicate and incomplete responses), 7,013 students remained in the sample for analysis. Of these $39 \%$ identified as male and $61 \%$ as female ${ }^{\mathrm{iv}}$. Comparing the gender profile to our younger sample of students (sample details published in Author 2 et al., 2015), we can see that the current sample contains proportionately less males (39\% vs $46 \%$ ) and more females (61\% vs $54 \%$ ). As the study focuses in part on the impact of ethnicity on students' aspirations, schools with higher populations of ethnic minority students were deliberately over-recruited to ensure sufficient numbers for analysis. Consequently, for example, there are fewer White students in the sample than in all primary and secondary schools in England. Students reported their ethnicities as follows: 76.5\% White, 10.0\% South Asian (Indian, Pakistani, Bangladeshi heritage), 4.3\% Black (Black African, Black Caribbean heritage), 1.8\% Chinese or East Asian, 5.8\% mixed or other, and $1.6 \%$ preferred not to say.

We also calculated a measure of 'cultural capital' (based on parental university attendance, leaving school before 16 , number of books in the home, and visits to museums) and created five cultural capital groups: very low (6.4\%), low (28.0\%), medium (26.4\%), high (20.3\%), and very high (18.9\%). For further justification for this scoring methodology please refer to (Author 2 et al., 2015). The ethnic and cultural capital profiles were very similar between samples.

Due to the discrepancy in gender between the comparison samples, the Year 13 data were weighted by gender to be identical to the gender distribution of the survey data published in 2015. Analyses of the weighted means of item frequencies and of latent variables 
did not differ significantly from the analyses using unweighted data. We therefore report analyses of the unweighted data. Because the discrepancies between the survey samples were smaller for other background characteristics (i.e. ethnicity, cultural capital) than for gender, it was unnecessary to weight the data for those characteristics.

The survey covered topics such as: aspirations (including a focus on science); subject preferences; participation in science activities in and out of school; parental and peer attitudes towards school and science; post-16 choices. At various phases in the project, focus groups were conducted with students to understand what they perceive by the term 'science' (when they encountered it in the survey). Students tended to interpret the term as referring to the 'pure'/school sciences, namely, Biology, Physics, and Chemistry. Drawing on our previous survey work, we calculated science capital from a 14-item scale (see Author 2 et al., 2015 and Author 3 et al., 2016 for detailed justification of methods). Table 1 below presents a summary of the items included in the index. These items were used to create a composite measure of science capital, which could be used in further analyses (such as the multivariate analyses incorporated below). Items were weighted according to their theoretical centrality to the notion of science capital (for instance, having a parent who worked in science was weighted more heavily than having a neighbor who worked in science). Scores were then summed across items, to generate a single science capital score for each young person. We do not claim that science capital is a single/unitary construct/factor (and therefore do not present reliability details for the index), but rather has a number of different dimensions which, together, influence an individual's relationship with science and are connected to the extent to which people feel that science is 'for me'. Correspondingly, our measure, or index, of science capital is a composite measure that captures these different facets of the construct. Students' science capital scores were transformed along a scale from 0-100 and we used this distribution of science capital scores to divide students into three groups - possessing low, medium, and high 
levels of science capital (see Author 2 et al. (2015) regression analyses providing further justification). We decided to simply group these into thirds, for conceptual ease, defining low science capital as the bottom third of scores on the $0-100$ scale (0-33.2), medium science capital scores as 33.3-66.5 and high science capital scores as 66.6-100 (the top value).

[Insert Table 1 about here]

Students were also asked to report which sets (if any) they are in at school for science when they were in Year $11^{\mathrm{v}}$. Science set (track) membership was as follows ${ }^{\mathrm{vi}}$ : top set: $59.0 \%$; middle/other set: $23.6 \%$; bottom set: $3.8 \%$; no sets for science: $13.7 \%$. Similarly, students were also asked about what science option they took in Year 11 and membership was as follows: Triple: $58.5 \%$; Double=35.2\%; Applied=2.5\%; Other=1.9\%; Don't Know=2.0\%. Of the 7,013 students, $610(8.7 \%)$ were not taking Advanced level ${ }^{\text {vii }}$ (A level) subjects or any science at school, 2,504 (35.7\%) were taking at least one A level science, $356(5.1 \%)$ were taking science but not A level (e.g. AS Levels, BTEC, diploma), and 3,530 (50.5\%) were taking A levels in non-science subjects. While appreciating that some classifications include Psychology, Computing, and Economics, for the purpose of this paper, we define science as including only Chemistry, Biology and Physics.

\section{Analyses}

A series of one-way ANOVAs with post-hoc tests were conducted to explore group differences (high, medium, low science capital) across a range of background factors (e.g. gender, ethnicity, course type). Transformation into z-scores for the analyses was unnecessary as the same items and scoring procedures were used for our science capital measure in both year groups. For categorical variables, descriptive cross-tabulation (chi-squared) analyses were 
conducted to explore the dataset and find basic relationships, with additional adjusted residual analyses performed (see Authors $1 \& 2$ [2017] for further justification of this procedure). It is important to be clear, that in this paper, we do not assume that the set of background characteristics investigated fully explains the variation in science capital reporting, but simply that they may be among the reasons for different patterns of response. We also acknowledge the potential for interaction between the background factors investigated, i.e. the possibility of individual factors working together with, or being mediated by, other background factors (e.g. Collins, 1999).

\section{Results}

Changes in science capital with age?

We begin by presenting the overall distribution of science capital scores for the cohort. These proportions were mirrored in our previous work using different, younger cohorts of students in England (Author 2 et al., 2015; Author 3 et al., 2016). On the present survey, 4.9\% (345 students) fell into high science capital group, while $62.4 \%$ (4,376 students) fell into the medium and $32.6 \%(2,288)$ fell into the low science capital group. Comparing the present findings to our previous work, this cohort has the same proportion of students classed as having 'high' science capital. The Year 13 data also shows that the proportion of students falling into the low science capital group increased compared to the younger cohort results $(32.6 \% \mathrm{vs}$ $27.2 \%)$ while the numbers in the medium science capital group have decreased $(62.4 \%$ vs 67.6\%). Results also showed that the overall mean for science capital has decreased from the younger sample $(M=41.57, S D=14.71)$ to the present, older sample $(M=41.00, S D=15.53$; $t(7,816)=1.86, p=.06, d=.04)$. 
While the ethnic and cultural capital profiles of the two samples were similar, the older sample contained proportionately more female students. As such, we would expect that the overall distribution of science capital would be shifted lower for this sample. Further, as the sample includes proportionately more A level science students (i.e. students taking at least one of physics, chemistry or biology at A level) than the national average (35.7\% vs $26.6 \%)$, the data was weighted by A-level science enrolment and gender. As results did not differ significantly from the unweighted data, we present unweighted results for ease of interpretation (and to avoid unbiased standard errors and estimates).

Through comparing these results across the samples, the overall distribution has widened, with more students in the older sample at the lower extreme (i.e. low science capital). In contrast, the overall picture of science capital in the older cohort seems to be more students at the 'low' end of the science capital spectrum with similar proportions of students at the 'high' end.

Gender and science capital

Independent sample t-tests showed that boys $(M=43.16, S D=15.59)$ had significantly higher science capital than girls $(M=39.61, S D=15.33)$ with Cohen's $d$ indicating small effect size $(t(7,007)=9.44, p<.001$, Cohen's $d=.23)$. This effect size is larger than our published results for students aged 11-16 $\left(d=.087 ; M_{\text {male }}=42.27, M_{\text {female }}=40.99\right)$.

\section{Ethnicity and science capital}

In line with our previous findings, science capital varied by ethnicity with ANOVA results (presented in Table 2) showing small, but significant differences in science capital 
scores among individuals from different ethnic backgrounds $\left(\eta \rho^{2}=.019\right)$. South Asian students are proportionately over-represented in the high science capital group, similar to the findings reported with the younger cohort (Author 2 et al., 2015), suggesting that ethnic differences in science capital remain stable between age 11-18 (with a similar small effect size reported for the younger cohort, $\left.\eta \rho^{2}=.015\right)$.

[Insert Table 2 about here]

\section{Cultural capital and science capital}

Science capital also appears to align closely with cultural capital, with ANOVA analyses showing significant differences such that the higher students' level of cultural capital, the higher their level of science capital, similar to previously published findings for the younger cohort. The effect size for the cultural capital ANOVA results was medium, indicating that $11 \%$ of the variance in science capital can be explained by cultural capital while a medium, approaching large, effect size $\left(\eta \rho^{2}=.21\right)$ was reported in the younger sample. In sum, the effect for cultural capital remains medium, but may be decreasing as students move through secondary school.

\section{Science capital and course outcomes at age 17/18}

An ANOVA was conducted to look at science capital scores across the different Year 13 course options. Results showed that students who were taking A level science at Year 13 had significantly higher levels of science capital than their peers taking non-science subjects at 
A levels and 'other' routes (both science and non-science). As seen in Table 2, the effect size was large, indicating that $33 \%$ of the variance in science capital can be explained by course option. In addition, students on most post-16 science routes recorded higher levels of science capital than students overall (taking any subject) on a particular route. For instance, overall $5.1 \%$ of all A level students recorded high science capital, but $11.2 \%$ of A level science students had high science capital (compared to $1 \%$ for A level non-science students). Similarly, $2 \%$ of all BTEC students reported high science capital, while 3.2\% of BTEC science students reported high science capital (compared to $1.5 \%$ having high science capital on non-science BTEC routes).

In the younger cohort (Author 2 et al., 2015), 37\% of high science capital students aspired to study one or more sciences at A level compared to $9 \%$ of low science capital students. Similarly, for the older cohort proportionately more students with high science capital were enrolled on A level science courses $(81.4 \%$ of high science capital students reported taking at least one A science level in the current sample vs $7.2 \%$ of low science capital students). As such, these 'outcomes' are patterned in a similar way to previous 'aspirations by science capital patterns', and actually are more pronounced in the older sample.

To explore the results further, a series of crosstabulation analyses were run to investigate associations between membership in the 'other' science group and student characteristics. Results showed significant associations for gender, ethnicity, cultural capital and course options. The group of 371 individuals taking 'other' science options had relatively more males than the overall sample (50\% vs $39 \%)$. This group also had proportionately less White students $(65.0 \%$ vs $76.3 \%)$ and more Black students $(10.0 \%$ vs $4.2 \%)$. The cultural capital profiles of this group were also different to the overall sample, with this group having relatively more students with very low cultural capital (9.3\% vs 6.5\%). Looking at the 577 students in the cohort who were taking BTEC (science or non-science), this group contained 
proportionately more students with low science capital (48.7\% vs. $32.6 \%$ whole sample). In comparison, of the 2,612 science A level students, $43.4 \%$ were male (compared to $39 \%$ of overall sample), proportionately fewer were White (71\% vs $76.3 \%)$, more were South Asian (12.7\% vs $10.0 \%)$ and fewer students had very low levels of cultural capital (4.6\% vs. 9.2\%) with relatively more students having very high levels of cultural capital (24.6\% vs $19.0 \%)$.

\section{Science capital and previous school science experiences}

ANOVAs were also conducted to investigate differences in science capital scores by students' self-reported previous school science allocation in Year 11 (two years prior to the present data collection, in the final year of compulsory school science). Results showed significant differences, with students who were placed in 'top' sets for science (and those whose schools did not set for science) having significantly higher science capital than students in both bottom and 'other' sets (with $\eta \rho^{2}=.087$ indicating a small effect size). Students in the top set were also overrepresented in the high science capital group, again similar to the relative comparisons presented for the younger cohort (Author 2 et al., 2015). Difference analyses also showed that students who took Triple science in Year 11 had significantly higher science capital scores at Year 13 compared to students who took Double, applied, and 'other' routes (with $\eta \rho^{2}=.11$ indicating a medium effect size). Like the setting results, students who took Triple science were overrepresented in the high science capital group.

\section{Science capital and post-18 intentions}

Students with high science capital were significantly more likely to report intentions to pursue university enrolment $\left(x^{2}(16,6065)=213.65, p<.001\right.$, with Cramer's V=.13 indicating a large effect for large table). Students with high science capital were also significantly less likely to report intentions to pursue apprenticeships (1.3\% vs $6.1 \%$ whole sample). Our analyses 
additionally showed that high science capital students were relatively more likely to intend to pursue a university subject in the sciences compared with other courses. For example, high science capital students were proportionately overrepresented among student intending to take physics at university (10.9\% of high science capital students intend to pursue physics vs $2.6 \%$ of total sample), chemistry (3.6\% vs $1.6 \%)$, medicine (16.0\% vs $5.9 \%)$, biology $(17.1 \%$ vs $7.0 \%$ whole sample), engineering (10.2 vs $4.8 \%$ ), science-related ( $7.6 \%$ vs $3.1 \%)$. Put differently, results showed that science capital is most strongly related to physics, with students with high science capital being 6.01 times more likely to report intention to pursue physics at university than students with medium and low levels of science capital followed by medicine $(\mathrm{OR}=3.50)$, biology $(\mathrm{OR}=3.06)$, science-related subjects $(\mathrm{OR}=2.93)$, chemistry $(2.52)$, and engineering $(\mathrm{OR}=2.46)$.

\section{Discussion}

The present findings advance our understanding of patterns of participation in science by allowing comparisons to be drawn with previous work. Through replicating results previously found with this cohort at age 11-16 (Author 2 et al., 2015, Author 3 et al., 2016), we have shown that the average level of science capital among young people at age 17/18 has decreased, and that science capital is spread unevenly. Compared to the younger sample, a smaller proportion of students possessed high science capital and a greater percentage had low science capital. Our findings therefore reinforce arguments that secondary school science is failing to provide young people with valuable forms of scientific cultural (and social) capital (Claussen \& Osborne, 2013).

We also argue that this trend may be exacerbated in the 15-18 age period; our finding that students' science capital decreases as they transition towards the end of secondary school is particularly surprising considering that our sample contains higher proportions of students 
who are taking A level science than seen nationally ( $36 \%$ vs $27 \%$ nationally). However, as the older sample is roughly representative of the wider population in terms of gender, ethnicity, cultural capital, school attainment and deprivation indicators, our analyses indicate that there is a widening gap in science capital post-16, which would suggest a need to look more widely at what shapes science capital as individuals progress through school.

Who has high/ low science capital at age 17/18?

Students with high science capital from the current survey (and our previous published work) were more likely to self-identify as male, South Asian, have higher levels of cultural capital and to have previously been in a top set for science at age $15 / 16$. In contrast, students in the low science capital group were more likely to have low or very low levels of cultural capital, were somewhat more likely to self-identify as White and female.

Comparing the results presented here to our previous findings (with students aged 1116), we can see that gender has a small but significant relationship to science capital, which increases with age (although it must be remembered that overall, the gender effect size remains small), such that boys are more likely to have higher levels of science capital. One possible interpretation could be that gender imbalances in A level STEM participation (particularly in physics, further mathematics and computing) may be contributing to this trend. We suggest that this finding could warrant further exploration - but at the least, suggests that gender inequalities in science may be likely to further exacerbate, rather than resolve, in the postcompulsory period.

Findings suggested that at age 17/18, cultural capital - our proxy measure for social class - still has the strongest relationship with students' levels of science capital out of the three main demographic axes investigated (cultural capital, ethnicity and gender). Medium effect 
sizes were reported in the older cohort, although this marks a slight decrease from the medium (approaching large) effect size reported for the younger cohort.

The findings reported in the ANOVA results in Table 2, lend support for our argument that cultural capital is not the same as science capital (see Author 2 et al., 2015). That is, our findings show how it is possible for a student to have high cultural capital (or even very high cultural capital) and not have high science capital - and conversely, for those with low or very low cultural capital to have high science capital vii. That is, while there is a relationship between the two, the science-specific element of aspects of habitus and forms of cultural and social capital are not reducible to general cultural and/or social capital and can be possessed independently of other forms of social, economic and cultural privilege or inequality. We propose, therefore, that science capital offers a particularly useful (and more focused) lens through which to illuminate and examine issues of science participation. While we previously compared the strength of the relationships between aspirations, cultural capital and science capital (Author 2 et al., 2015), future hierarchical regression analyses are planned to explore this in more depth. Specifically, we plan to explore the strength of the relationship between cultural capital and taking a science course, net of demographics, and whether or not any further unique variance is explained by subsequently adding science capital into the regression. It would also be worthwhile to explore whether science capital mediates the cultural capital effect.

Similar to findings reported by Wong (2015), small effect sizes for ethnicity were reported among both samples, suggesting that ethnic patterns in science capital may be 'set' at an earlier age and then remain relatively stable. . The differences in patterns of gender, cultural capital and ethnicity also point to the highly socially constructed nature of science capital that is, it does not simply increase or decrease with age, but is differentially shaped by different 
social structures, indicating a complex intersectionality which, we believe, warrants further attention.

The impact of earlier school science experiences?

The present findings show that the impact of prior school science setting from 2-4 years previous, seems to have a clear relationship with students' levels of science capital at age $17 / 18$, such that students who self-reported having been in top set science classrooms in the final years of compulsory science, had the highest levels of science capital at age 17/18. Building on the findings of Author 2 et al. (2015) which showed the immediate relationship of setting to students' levels of science capital at age 11-16, the present results may suggest that the impact of school grouping practices can still persist (several years) after. In line with previous findings that those age 11-16 who attended schools where they were not set for science reported as positive attitudes to science as those who were in top sets (ibid.), we interpret the present findings as adding further weight to existing evidence regarding the negative effects of setting for those placed in the lower sets (Authors 2017; Steenbergen-Hu, Makel, OlszewskiKubilius, 2016; Ireson, Hallam, Hurley, 20015;).

Findings also showed a relationship between science capital at age 17/18 and students' previous science route allocation in the final two years of compulsory science education, such that those on the most prestigious ('Triple' science) route had higher science capital at age $17 / 18$ than those who had taken other routes. We interpret this finding as reinforcing our previous arguments regarding the inequitable nature and impact of these different structures/routes within the English education system (Author 2 et al., 2016) and adds weight to calls for review of the system, with a view to a single science route for all for high stakes national examinations at age 15/16 (e.g. IOP, 2018). 
The relationship between science capital and post-compulsory routes at age 17/18

Previously, we found that at age 11-16, students with higher levels of science capital were more likely to report intentions to pursue a science subject at university. Our new findings extend this understanding by showing the relationship between science capital and progression (what courses students are actually taking) at age 17/18, showing that high levels of science capital relate to a significantly greater likelihood of students taking a science course at age 17/18. In England, the main route into post-compulsory participation in science is via A levels. Unsurprisingly, students on most post-16 science routes (A levels) recorded higher levels of science capital than students overall (i.e. taking any subject).

These findings may be explained partly due to differences in the social, economic and ethnic profiles of the routes, with A level science students being much more socially advantaged (e.g. $49 \%$ high/very high cultural capital and 25\% low/very low cultural capital) than those taking the alternative BTEC science qualifications (19\% high/very high cultural capital and 53\% low/very low cultural capital) and 5\% of A level Science students selfreporting as Black, compared with $11 \%$ of BTEC science students. Arguably, the differences between students taking the two sorts of course reflect status differentials, with A levels being widely regarded as the 'gold standard' academic route for university entrance, whereas BTEC is a more vocational, lower status qualification. These findings echo other work which has shown that students pursuing science at A-level tend to be higher attaining and from higher social class backgrounds, although analysis suggests that this is largely due to classed differences in attainment (Nunes et al., 2017; Strand 2007; 2011).

While it is difficult to draw firm conclusions from these data, we suggest that one potential interpretation is that less socially advantaged students who are interested in science 
are more likely to be channelled on to lower status courses, irrespective of high levels of science capital. We suggest that a further interpretation may be that while high science capital relates to and is useful/important for supporting students to continue with science, that wider inequalities may mediate this relationship, such that students from working class and some minority ethnic communities are less likely to be able to access high status post-16 courses.

The relationship between science capital and post-18 aspirations

We previously found a significant relationship at age 11-16 between a student's level of science capital and their A level and degree aspirations (Author 2 et al., 2015). The present findings replicate and extend these findings, showing that at age 17/18, students with high science capital are significantly more likely to aspire to study science (especially Physics) and science-related subjects at university degree level. We interpret the increasing gender effect and the strong relationship between high science capital and physics and engineering aspirations and attitudes as suggesting that dominant masculine associations between science (but particularly the physical sciences and engineering) may be exacerbated during the 16-18 age period. These findings have particular relevance for science teaching as science engagement has been shown to be 'infused' with identity work (Gazley et al., 2014).

\section{Recommendations for policy and practice}

Given that our work is underpinned and driven by a commitment to equity, we are interested in how science capital might be used as a transformative concept within science education to support increased and widened, more equitable participation in science. In this respect, we suggest that the $22 \%$ of students within the survey who were identified as having low science capital would seem to constitute a key group deserving of (urgent) resources and 
intervention - and this attention may be particularly beneficial given that most of this group no longer study science in any formal educational way. We also call for further critical attention to be given to the differential science routes that exist in the English school system, to the continued significance of cultural capital and to the increasing gender effect between ages 1118. In particular, we suggest that the growing gap at 17/18 between those with high science capital and others poses an urgent question as to how to not just widen STEM participation for bolstering of the 'pipeline' but also the need to widen the social backgrounds of students' reporting high levels of science capital for public scientific literacy and active citizenship.

Our research raises the question as to whether the patterns identified in this paper are immutable or whether they are open to intervention and change? For instance, can science capital be 'built'? Wider work, conducted with secondary school science teachers and their classes, suggests that implementation of a teaching approach based on the principles of broadening ways of being and doing science, personalising and localising science content to students' diverse lives and building the attitudinal and behavioural aspects of science capital can produce significant increases in student science capital (Authors 2017; Authors, 2017). Research has also been conducted showing the benefits of similar teaching approaches (drawing from students' prior experiences) in out-of-school informal science learning (Gonsalves, Rahm, \& Carvalho, 2013). However, the present paper raises the question as to how this might be achieved with young people who no longer study science at age $17 / 18$ if we are to close the science capital gap?

We also interpret the findings reported here as raising questions about the value of specialisation versus a broad and balanced curriculum to age 18 (e.g. Authors, 2015). That is, if levels of science capital typically only increase amongst those who study science post-16 and are already socially advantaged, then how might we reach others (especially given that the 
current English education system of early specialisation means that many students do not continue with science after the age of 16). In contrast, a baccalaureate style qualification enables students to study more, and a wider mix, of subjects, which could potentially provide a mechanism for engaging more young people with science for longer (and potentially further building science capital).

We suggest that further consideration might usefully be given to the role and potential of the informal science sector for supporting young people's science capital post-16, especially for those no longer studying science in formal education.. However, as existing literature notes (Dawson, 2019; Feinstein \& Meshoulam, 2014), currently many informal science learning settings, such as science centres and museums predominantly serve more socially advantaged communities and often fail to reach working-class and minority ethnic communities. In any case, we suggest that the inequalities described here with regard to findings from 17/18 year olds, suggests that there is a further need for work that is aimed at promoting empowering (Tan \& Calabrese Barton, 2012; Calabrese Barton \& Yang, 2000) science teaching, learning, and participation within schools, 'informal' science learning contexts, and within families.

\section{Recommendations for further research}

Perhaps unsurprisingly, our data shows that science capital is strongly socially patterned, being concentrated in more privileged social groups. The findings show that the distribution of science capital remains gendered, classed and racialized although .cultural capital seems to have a stronger association to science capital, with gender and ethnicity effect sizes remaining small across the cohort comparisons. However, the gender effect size was shown to increase from the aged 11-16 cohort to the older 17/18 year old cohort. 
We urge policy consideration of these findings, as well as future research exploring the relationship between science capital beyond demographic factors to understand the relative strength of these associations. While demographic factors may not be the primary influences of science capital, we would argue that any interventions or policy attempts to foster the development of science capital do need to take these factors into account as all students can benefit.

Our conceptual work and analyses inevitably raise a further set of questions. How, and in what contexts, might different sorts of capital be mobilized and used to increase science capital? Given that the value of capital is determined by field, how is the value of science capital socially defined across different contexts? And what might science capital look like in other national contexts, given that the components our work has identified may not have the same value elsewhere?

\section{Limitations}

While this paper offers several new insights, a number of limitations need to be addressed. For example, the results presented relate to survey data and therefore do not escape the limitations of similar self-report measures. In addition to issues of internal validity, several issues regarding the external validity of the research presented in this paper also need to be addressed. While the results presented can arguably be generalised to secondary school students in England, wider cultural comparisons need to be made cautiously. Moreover, while schools were encouraged to invite a broad range of classes and attainment groups to participate, it is possible that gatekeepers selectively identified participants (e.g. higher attaining students/classes). Schools that consented to participate may be atypical in having higher morale, less fear of inspection and more desire for improvement and development, which may further affect the external reliability of the results (Campbell \& Stanley 1966). We also 
acknowledge the limitations of any direct comparisons made between the older and younger samples and appreciate the selectivity of the post-16 population, especially considering major changes seen in the UK science exam structure in recent years (see Strand, 2017 for a detailed discussion).

Methodologically, chi-squared tests are very sensitive to sample size, with the size of the calculated chi-square being directly proportional to the size of the sample (regardless of the strength of the relationship between the variables). However, following the suggestions of García-Pérez and Núñez-Antón (2003), we performed adjusted residual analyses and reported effect sizes (Cramer's V), which allow us to make important interpretations regarding the practical significance of any associations that were found. Regarding this, while we appreciate that not all effect sizes presented in this paper were large, we argue in line with findings that suggest that inequalities accumulate over time, through multiple repeating social relational contexts and small biasing effects (Ridgeway \& Correll, 2004). In this, any differences in science capital by student characteristics in secondary school may lead to much larger effects later on.

We additionally acknowledge that a quantitative tool may not be able to capture the complexity of science capital. However, through conducting repeated in-depth interviews alongside the surveys, our wider project work covers both the breadth and depth of participants' perspectives, therefore reducing threats to validity.

\section{Conclusions}

This paper provides further evidence and insights for growing understanding of how science-related resources are unevenly socially spread within society—and the implications of 
this uneven spread for young people's participation in science. This work suggests that while science capital remains spread unevenly, with a similar, relatively small proportion of students possessing high science capital between the ages of 11 and 18, an increasing percentage are classified as having low science capital. These findings may support arguments that secondary school science in the UK is not providing young people with the most valuable forms of scientific cultural (and social), and that reform may be required post-16 to support wider engagement with science.

The present paper shows that science capital is patterned in inequitable ways, replicating previous results (from students aged 11-16) among students who are approaching the end of secondary school (aged 17/18). Analyses additionally demonstrate that students with high science capital were more likely to have been enrolled on the prestigious Triple science route in the UK (a route often considered the gate-way to further academic study in science post-16 and after school). Findings also showed that science capital was related to students' post-18 study intentions, with high science capital students being more likely to report intentions on university study in STEM and STEM-related subjects. By analysing differences in science capital by student characteristics, the present results add to our understanding of potential ways of redressing the patterned nature of science participation both in school and at post-secondary level. 


\section{References}

Author 1 and 2 (2017)

Author 2 et al. $(2017 ; 2016 ; 2015 ; 2014 ; 2013)$

Author 3 et al. $(2016 ; 2014 ; 2011)$

Anonymised (2017)

Anonymised (2015)

Anonymised (2011)

Aschbacher, Li, Roth (2010). Is science me? High school students' identities, participation and aspirations in science, engineering and medicine. Journal of Research in Science Teaching, 47(5), 564-582.

BIS (Department for Business, Innovation and Skills). (2008). A Vision for Science and Society: A consultation on developing a new strategy for the UK. London: Department for Business, Innovation and Skills. Retrieved from <https://www.gov.uk/government/publications/a-vision-for-science-and-society--2>.

BIS. (2011). Science, technology, engineering and maths graduates in non-STEM jobs. London: Department for Business, Innovation and Skills. Retrieved from <https://www.gov.uk/government/publications/science-technology-engineering-and-mathsgraduates-in-non-stem-jobs>.

BIS. (2014, January). Insights from international benchmarking of the UK science and innovation system (Analysis Paper Number 03). London: Department for Business, Innovation and Skills. Retrieved from <https://www.gov.uk/government/uploads/system/uploads/attachment_data/file/277090/bis- 
14-544-insights-from-international-benchmarking-of-the-UK-science-and-innovation-systembis-analysis-paper-03.pdf>.

Bourdieu, P. (2010). Sociology is a martial art. New York, NY: New Press.

Bourdieu, P., \& Passeron, J.-C. (1990). Reproduction in education, society and culture (Vol. 4). London: Sage.

Calabrese Barton, A., \& Tan, E. (2010). We be burnin'!: Agency, Identity and Learning in a Green Energy Program. Journal of the Learning Sciences 19(2), 187-229. DOI: $10.1080 / 10508400903530044$.

Calabrese Barton, A., \& Yang. (2000). The cultural of power and science education: Learning from Miguel. Journal of Research in Science Teaching, 37 (8), 871-889.

Campbell, D. T., \& Stanley, J. C. (1966). Experimental and Quasi-Experimental Designs for Research. Chicago, IL: Rand-McNally.

Carlone, H. B. (2003). (Re)producing good science students: Girls' participation in high school physics. Journal of Women and Minorities in Science and Engineering, 9(1), 17-34. DOI: 10.1615/JWomenMinorScienEng.v9.i1.20.

Carter, L. (2008). Globalization and science education: The implications of science in the new economy. Journal of Research in Science Teaching, 45(5), 617-633. DOI 10.1002/tea.20189

Claussen, S., \& Osborne, J. ( 2013). Bourdieu's notion of cultural capital and its implications for the science curriculum. Science Education, 97(1), 58-79. DOI: 10.1002/sce.21040.

Collins, P. H. 1999. “Moving beyond Gender: Intersectionality and Scientific Knowledge.” In M. M. Ferree, J. Lorber, and B. B. Hess (Eds.), Revisioning Gender, (pp. 261-284). Thousand Oaks, CA: Sage. 
Daly, A., Grant, L., \& Bultitude, K. (2009). Girls into physics - action research (Research brief DCSF-RB103). London: Department for Children, Schools and Families. Retrieved from <http://eprints.uwe.ac.uk/12427>.

Darke, K., Clewell, B., \& Sevo, R. (2002). Meeting the Challenge: The Impact of the National Science Foundation's Program for Women and Girls. Journal of Women and Minorities in Science and Engineering, 8(3-4), 285-303. DOI: 10.1615/JWomenMinorScienEng.v8.i3-4.30.

Dawson, E (2019). Equity, Exclusion and Everyday Science Learning: The experiences of Minoritised Groups. London: Routledge.

Essex, J., \& Haxton, K. (2018). Characterising patterns of engagement of different participants in a public STEM-based analysis project. International Journal of Science Education, Part B, 8(2), 178-191. DOI: 10.1080/21548455.2017.1423128.

Feinstein, N.W., \& Meshoulam, D. (2014). Science for what public? Addressing equity in American science museums and science centers. Journal of Research in Science Teaching, 51(3), 368-394. DOI 10.1002/tea.21130

Francis, B., Connolly, P., Archer, L., Hodgen, J., Mazenod, A., Pepper, D., Sloan, S., Taylor, B., Tereshchenko, A., Travers, M. (2017). Attainment Grouping as self-fulfilling prophesy? A mixed methods exploration of self confidence and set level among Year 7 students. International Journal of Educational Research, 86, 96-108. DOI: 10.1016/j.ijer.2017.09.001.

Gazley, J.L., Remich, R., Naffziger-Hirsch, M.E., Keller, J., Campbell, P.B., \& McGee, R. (2014). Beyond preparation: Identity, cultural capital, and readiness for graduate school in the biomedical sciences. Journal of Research in Science Teaching, 51(8), 1021-1048. DOI10.1002/tea.21164 
Godwin, A., Potvin, G., Hazari, Z., \& Locket, R. (2016). Identity, Critical Agency, and Engineering: An Affective Model for Predicting Engineering as a Career Choice. Journal of Engineering Education, 105(2), 312-340. DOI: 10.1 002/jee.20118.

Gokpinar, T., \& Reiss, M. (2016). The role of outside-school factors in science education: a two-stage theoretical model linking Bourdieu and Sen, with a case study. International Journal of Science Education, 38(8), 1278-1303. DOI: 10.1080/09500693.2016.1188332.

Gonsalves, A., Danielsson, A., \& Petterson, H. (2016). Masculinities and experimental practices in physics: The view from three case studies. Physical Review Physics Education Research, 12(020120), 1-15. DOI: 10.1103/PhysRevPhysEducRes.12.020120.

Gonsalves, A., Rahm, J. \& Carvalho, A. (2013). "We could think of things that could be science": Girls' re-figuring of science in an out-of-school-time club. Journal of Research in Science Teaching, 50(9), 1068-1097. DOI 10.1002/tea.21105

García-Pérez, M. A., and V. Núñez-Antón. 2003. Cellwise Residual Analysis in Two-way Contingency Tables. Educational and Psychological Measurement 63 (5), 825-839. doi:10.1177/0013164403251280.

Haussler, P., \& Hoffmann, L. (2002). An intervention study to enhance girls' interest, selfconcept, and achievement in physics class. Journal of Research in Science Teaching, 39(9), 870-888. DOI: 10.1002/tea.10048.

HM Treasury. (2011, March). The Plan for Growth. London: Department for Business, Innovation and Skills \& HM Treasury. Retrieved from <https://assets.publishing.service.gov.uk/government/uploads/system/uploads/attachment_dat a/file/221514/2011budget_growth.pdf >.

Hurd, P.D. (2002). Modernizing Science Education. Journal of Research in Science Teaching, 39(1), 3-9. DOI 10.1002/tea.10006 
Institute of Physics (2018). Why not physics? A snapshot of girls' uptake at A-level. London, Institute of Physics. < https://www.iop.org/publications/iop/2018/file_71495.pdf>

Institute of Physics. (2015). Opening Doors A guide to good practice in countering gender stereotyping in schools. London: Institute of Physics. Retrieved from <https://www.iop.org/publications/iop/2015/file_66429.pdf>.

Ireson, J., Hallam, S., \& Hurley, C. (2005). What Are the Effects of Ability Grouping on GCSE Attainment? British Educational Research Journal, 31(4), 443-458. Retrieved from http://www.jstor.org/stable/30032578.King, H. Nomikou, E., Archer, L., \& Regan, E. (2015). Teachers' Understanding and Operationalisation of 'Science Capital', International Journal of Science Education, 37(18), 2987-3014. DOI: 10.1080/09500693.2015.1119331.

Luehmann, A. L. (2009). Students' perspectives of a science enrichment programme: Out-ofschool inquiry as access. International Journal of Science Education, 31(13), 1831-1855. DOI: $10.1080 / 09500690802354195$.

Mendick, H. (2005). A beautiful myth? The gendering of being/doing 'good at maths'. Gender and Education, 17(2), 203-219. DOI: 10.1080/0954025042000301465.

Mujtaba, T., \& Reiss, M. J. (2014). A survey of psychological, motivational, family and perceptions of physics education factors that explain 15-source-old students' aspirations to study post-compulsory physics in English schools. International Journal of Science and Mathematics Education, 12(2), 371-393. DOI: 10.1007/s10763-013-9404-1.

Mujtaba, T., \& Reiss, M. J. (2016). “I Fall Asleep in Class ... But Physics Is Fascinating”: The Use of Large-Scale Longitudinal Data to Explore the Educational Experiences of Aspiring Girls in Mathematics and Physics. Canadian Journal of Science, Mathematics and Technology Education, 16(4), 313-330. DOI: 10.1080/14926156.2016.1235743. 
Mujtaba, T., Sheldrake, R., Reiss, M., \& Simon, S. (2018). Students' science attitudes, beliefs, and context: associations with science and chemistry aspirations, International Journal of Science Education, 40:6, 644-667, DOI: 10.1080/09500693.2018.1433896

National Audit Office (NAO). (2018). Delivering STEM (science, technology, engineering and mathematics) skills for the economy. London: National Audit Office. Retrieved from $<$ https://www.nao.org.uk/report/delivering-stem-science-technology-engineering-andmathematics-skills-for-the-economy/>.

Osborne, J. (2007). Science Education for the Twenty First Century. Eurasia Journal of Mathematics, Science \& Technology Education, 3(3), 173-184. DOI: 10.12973/ejmste/75396.

Raelin, J.A., Bailey, M.B., Hamann, J., Pendleton, L.K., Reisberg, R., \& Whitman, D.L. (2014). The gendered effect of cooperative education, contextual support, and self-efficacy on undergraduate retention. Journal of Engineering Education, 103(4), 599-624. DOI: 10.1002/jee.20060.

Ridgeway, C. L., \& Correll. S. J. (2004). Unpacking the Gender System: A Theoretical Perspective on Gender Beliefs and Social Relations. Gender \& Society, 18(4), 510-531. DOI: 10.1177/0891243204265269.

Rothwell, J. (2014). Still Searching: Job Vacancies and STEM Skills. Washington, DC: Brookings Institution. $\quad$ Retrieved from: http://www.brookings.edu/ /media/research/files/reports/2014/07/stem/job\%20vacancies\%20 and $\% 20$ stem $\% 20$ skills.pdf.

Royal Academy of Engineering. (2012). Educating engineers to drive the innovation economy. London: Royal Academy of Engineering. Retrieved from <https://www.raeng.org.uk/publications/reports/innovation-economy-2012>. 
Royal Academy of Engineering. (2016). The UK STEM Education Landscape: A report for the Lloyd's Register Foundation from the Royal Academy of Engineering Education and Skills Committee. London: Royal Academy of Engineering. Retrieved from <http://www.raeng.org.uk/publications/reports/uk-stem-education-landscape>.

Salehjee, S., \& Watts, M. (2015). Science Lives: School choices and 'natural tendencies', International Journal of Science Education, 37(4), 727-743, DOI: 10.1080/09500693.2015.1013075

Smart, S., \& Rahman, J. (2009). Bangladeshi girls choosing science, technology, engineering and maths: An exploration of factors that affect Bangladeshi girls' achievement in, engagement with, and aspirations in STEM subject areas (Research conducted in the London Borough of Tower Hamlets 2007-2008). Reading, UK: CfBT Education Trust. Retrieved from <https://www.educationdevelopmenttrust.com/ /media/cfbtcorporate/files/research/2008/rbangladeshi-girls-choosing-stem-full-2008.pdf>.

Smith, E. (2010a). Do we need more scientists? A long-term view of patterns of participation in UK undergraduate science programmes. Cambridge Journal of Education, 40(3), 281-298. DOI: 10.1080/0305764X.2010.502886.

Smith, E. (2010b). Is there a crisis in school science education in the UK? Educational Review, 62(2), 189-202. DOI: 10.1080/00131911003637014.

Nunes, T., Bryant, P., Strand. S., Hillier, J., Barros, R. \& Miller-Friedmann, J. (2017). A review of SES and science learning in formal educational settings. London: Educational Endowment Foundation.Steenbergen-Hu, S., Makel, M. C., \& Olszewski-Kubilius, P. (2016). What One Hundred Years of Research Says About the Effects of Ability Grouping and Acceleration on K-12 Students' Academic Achievement: Findings of Two Second-Order 
Meta-Analyses. Review of $\quad$ Educational $\quad$ Research, 86(4), 849899. https://doi.org/10.3102/0034654316675417

Strand, S. (2007). Minority ethnic students in the Longitudinal Study of Young People in England (Research Report RR-002). London: Department for Children, Schools and Families. Strand, S. (2011). The limits of social class in explaining ethnic gaps in educational attainment. British Educational Research Journal, 37(2), 197-229. DOI: 10.1080/01411920903540664.

Strand. S. (2017). Identifying the link between socio-economic disadvantage and participation and attainment in science: An analysis of the England National Pupil Database (NPD). In Nunes, T., Bryant, P., Strand. S., Hillier, J., Barros, R. \& Miller-Friedmann, J. (2017). A review of SES and science learning in formal educational settings. London: Educational Endowment Foundation.

Tan, E., Calabrese Barton, A., Turner, E., \& Varley Gutiérrez, M. (2012). Empowering science and mathematics education in urban schools. Chicago: University of Chicago Press.

Tereshchenko, A., Francis, B., Archer, L., Hodgen, H., Mazenod, A., Taylor, B., Pepper, D. \& Travers, M. (2018). Learners' attitudes to mixed-attainment grouping: examining the views of students of high, middle and low attainment. Research Papers in Education, DOI: $10.1080 / 02671522.2018 .1452962$

UK Commission for Employment and Skills. (2013, November). The Supply of and Demand for High-Level STEM Skills (Evidence Report 77). London: UK Commission for Employment and Skills.

UK Commission for Employment and Skills. (2014, December). Careers of the future. London: UK Commission for Employment and Skills. 
US President's Council of Advisors on Science and Technology. (2010). Report to the President: Prepare and Inspire: K-12 education in science, technology, engineering, and math $\begin{array}{lllll}\text { (STEM) for } & \text { America's } & \text { future. } & \text { Retrieved }\end{array}$ <https://obamawhitehouse.archives.gov/administration/eop/ostp/pcast/docsreports>.

Vedder-Weiss, D. (2018). “Won't you give up your snack for the sake of science?” Emerging science identities in family everyday interaction. Journal of Research in Science Teaching, 55, 1211-1235. DOI: 10.1002/tea.21449

Wong, B. (2015). Careers "From" but not "in" science: What are aspirations to be a scientist challenging for minority ethnic students? Journal of Research in Science Teaching, 52(7), 9791002. DOI10.1002/tea.21231

Wong, B. (2012). Identifying with science: a case study of two 13-year-old 'high achieving working class' British Asian girls. International Journal of Science Education, 34(1), 43-65. DOI: 10.1080/09500693.2010.551671.

Wynne, B. (2014). Further disorientation in the hall of mirrors. Public Understanding of Science 23(1), 60-70. DOI: 10.1177/0963662513505397. 
Table 1.

A summary of the items included in the science capital index.

Item
A science qualification can help you get many different
types of job.
When you are NOT in school, how often do you talk
about science with other people?
One or both of my parents think science is very
interesting.
One or both of my parents have explained to me that
science is useful for my future.

I know how to use scientific evidence to make an argument.

When not in school, how often do you read books or magazines about science?

When not in school, how often do you go to a science centre, science museum or planetarium?

When not in school, how often do you visit a zoo or aquarium?

How often do you go to after school science club?

My teachers have specifically encouraged me to continue with science after GCSEs.

My teachers have explained to me science is useful for my future.

It is useful to know about science in my daily life.

Who do you talk to about science? Who are they?

Do you know anyone who works in science? Who are they?
Response options and weighting

-2 for strongly disagree, -1 for disagree, 0 for neither, 1 for agree, 2 for strongly agree

-2 for never, -1 at least once a year, 0 at least once a term, 1 at least once a month, 2 at least once a week

-1 for strongly disagree, -0.5 for disagree, 0 for neither, 0.5 for agree, 1 for strongly agree

-1 for strongly disagree, -0.5 for disagree, 0 for neither, 0.5 for agree, 1 for strongly agree

-2 for strongly disagree, -1 for disagree, 0 for neither, 1 for agree, 2 for strongly agree

-2 for never, -1 at least once a year, 0 at least once a term, 1 at least once a month, 2 at least once a week

-2 for never, -1 at least once a year, 0 at least once a term, 1 at least once a month, 2 at least once a week

-2 for never, -1 at least once a year, 0 at least once a term, 1 at least once a month, 2 at least once a week

-2 for never, -1 at least once a year, 0 at least once a term, 1 at least once a month, 2 at least once a week

-2 for strongly disagree, -1 for disagree, 0 for neither, 1 for agree, 2 for strongly agree

-2 for strongly disagree, -1 for disagree, 0 for neither, 1 for agree, 2 for strongly agree

-1 for strongly disagree, -0.5 for disagree, 0 for neither, 0.5 for agree, 1 for strongly agree

0.5 for parents or carers, 0.5 for extended family, 0.5 for friends, 0.5 for siblings, 0.5 for directly with scientists, 0.5 for teachers, 0.5 for other, 0 for no one

2 for 'parents or carers, 1 for siblings, 1 for extended family members, 1 for other 
Table 2.

A summary of ANOVA analyses investigating differences in science capital by Year 13 student characteristics $(\mathrm{N}=7,013 ; M=41.00, S D=15.53)$.

\begin{tabular}{|c|c|c|c|c|c|c|}
\hline Group & $\begin{array}{l}\text { Science Capital } \\
M(S D)\end{array}$ & $\mathbf{F}$ & df & $p$ & $\eta \rho^{2}$ & $\begin{array}{l}\text { Significant post hoc } \\
\text { comparisons }\end{array}$ \\
\hline \multicolumn{7}{|l|}{ Ethnicity } \\
\hline Black & $43.90(15.54)$ & & & & & Black vs White \\
\hline Asian & $44.82(15.30)$ & & & & & Asian vs White \\
\hline White & $39.88(15.49)$ & & & & & Chinese vs White \\
\hline Chinese & $47.73(14.53)$ & & & & & Other vs White \\
\hline Other & $44.92(14.25)$ & & & & & \\
\hline Prefer not to say & $40.91(15.92)$ & 26.62 & 5,7003 & $<.001$ & .019 & \\
\hline \multicolumn{7}{|l|}{ Cultural Capital } \\
\hline Very Low & $30.96(14.73)$ & & & & & All comparisons \\
\hline Low & $35.96(14.67)$ & & & & & significant \\
\hline Medium & 41.09 (14.43) & & & & & \\
\hline High & $44.35(15.16)$ & & & & & \\
\hline Very High & $48.12(14.60)$ & 206.27 & 4,7004 & $<.001$ & .11 & \\
\hline \multicolumn{7}{|l|}{ Science Set } \\
\hline Top & $44.51(15.58)$ & & & & & Top vs Bottom \\
\hline Bottom & $31.87(15.19)$ & & & & & Top vs Other \\
\hline Other & 34.40 (14.39) & & & & & No set vs Bottom \\
\hline No Set & $45.05(15573)$ & 193.74 & 3,6067 & $<.001$ & .087 & \\
\hline \multicolumn{7}{|l|}{ Science Option } \\
\hline Double & $35.66(14.83)$ & & & & & Triple vs Double, App, \\
\hline Triple & $46.12(15.16)$ & & & & & Other, Don't Know \\
\hline Applied & $30.44(13.55)$ & & & & & Applied vs Double, \\
\hline Other & $34.87(16.27)$ & & & & & Don't know \\
\hline Don't Know & $39.53(18.28)$ & 188.64 & 4,6062 & $<.001$ & .11 & \\
\hline \multicolumn{7}{|l|}{ Science Course } \\
\hline Non-science Other & $31.94(14.17)$ & & & & & All comparisons \\
\hline Non-science A level & $33.97(12.88)$ & & & & & significant \\
\hline Science A level & $52.04(12.14)$ & & & & & \\
\hline Science Other & $48.80(13.03)$ & 1131.04 & 3,7005 & $<.001$ & .33 & \\
\hline
\end{tabular}




\footnotetext{
'At the age of 16 (Year 11) students take national examinations (GCSEs) where they generally choose three or four subjects to specialise in (beyond the core Maths, English, and Science). Students then have the option to study multiple routes including; A level (considered the prestigious route to university entrance), AS level, BTEC (more applied training route) and IB. After the age of 16 students are required to remain in education or formal training until the age of 18. Currently, science at GCSE can be taken either as a combined single subject (which is worth two GCSEs. Double Science) or as the three separate subjects of physics, chemistry and biology (each worth a single GCSE in its own right, Triple Science).

ii The data analysed is generated by the Economic and Social Research Council-funded '[Name]'project. The longitudinal study, and its predecessor [Name] study, have been tracking and exploring children's science and career aspirations from age 10-19. Methods include a quantitative online survey of the cohort and repeat interviews with a sub-sample of students and their parents. This paper draws on survey and interview data from students age 17/18 years old (Year 13). The study subscribes to the ethical standards of the British Educational Research Association, and has been approved by the [anonymised] ethics committee.

iii The index of multiple deprivation is a government measure of social and economic deprivation in England. It comprises seven main aspects of deprivation: income, employment, health \& disability, education, skills \& training, housing, crime and living environment.

iv We are aware that we are oversimplifying gender and agree that it is not a binary construction. However, going into the level of detail that reflects the complexity of gender was far beyond the scope our survey. In addition, an extremely small proportion declined to respond to the question. Thus, for the sake of parsimony, we have decided to use a simplified construction of gender in this paper - focusing on 'males' and 'females'. $\mathrm{v}$ In the UK, some schools organise students into attainment sets for science based on exam results. On the present survey, students were asked if they were in top, middle, bottom, or some other set. Students were also asked whether or not their schools organised them into sets for science. Students' self-reported responses were used in the analyses and we are aware that these may not accurately reflect what set an individual student was in as they are based on students' perceptions. However, it is generally quite clear to students what set they have been placed in.

vi That almost 50\% of students reported being in the top sets for science suggests that there was also a tendency on the part of schools to ask students in top sets to complete the survey. However, we are unable to weight the data for set, as there is no way of knowing what proportion of students, nationally, are in top sets. This situation is further complicated by the fact that different schools have different proportions of students in their top set (some might have two classes of top sets, while others might have one, or three) and different schools place students in sets based on different criteria.

vii In the UK, students at aged 15/16 have the option to take various study routes including Advanced Levels (A levels), AS levels, BTEC (a more applied training route), and International Baccalaureate. The A level route is generally considered a prestigious route, leading on to post-secondary study at university.

Note that the table shows that even the very high cultural capital students would not be grouped into the 'high' viii science capital group (which has a cut off of 70). We do however appreciate that it could also be argued here that the 70 cut off is possibly too high, a separate issue which we are exploring.
} 